\title{
EDUCAÇÃO SUPERIOR NA PERSPECTIVA DO SISTEMA E DO PLANO NACIONAL DE EDUCAÇÃO
}

\author{
Pedro Goergen*
}

\begin{abstract}
RESUMO: O presente ensaio se propõe destacar e comentar alguns dos aspectos centrais do Documento Final da Conferência Nacional de Educação (CONAE, 2010) no que se refere ao aspecto da educação superior. Para alcançar este objetivo, o trabalho inicia com um desenho do cenário político-econômico global e latinoamericano, com destaque para as políticas neoliberais, impostas aos países da região, a partir dos anos 1990 . Num passo seguinte, procede a uma breve análise da educação superior brasileira, no intuito de esclarecer como e em que medida as políticas neoliberais globais interferem na educação superior nacional. Finalmente e com base nas consideraçōes anteriores, faz uma sucinta análise das referências sobre educação superior, contidas no Documento Final da CONAE (2010). Conclui manifestando a esperança de que a efetivação do Sistema Nacional de Educação ajude a resgatar a dívida histórica do Estado de garantir uma educação de qualidade, em todos os níveis, para todo o povo brasileiro.
\end{abstract}

Palavras-chave: Educação superior. Sistema Nacional de Educação. Plano Nacional de Educação. CONAE 2010. Neoliberalismo.

\section{Higher edUCATION IN THE PERSPECTIVE OF THE NATIONAL EDUCATION SYSTEM AND OF THE NATIONAL PLAN FOR EDUCATION}

ABSTRACT: This essay highlights and comments some aspects of the final considerations of the National Conference on Education (2010 CONAE) with regard to higher education. To do so, it first outlines the global and Latin-American political-economical

Doutor em Educação, professor titular da Universidade de Sorocaba (UNISO) e professor titular colaborador da Universidade Estadual de Campinas (UNICAMP).E-mail: goergen@unicamp.br 
setting, by stressing the neoliberal policies imposed on the countries of the latter region, from the 1990s on. It then briefly analyses Brazilian higher education to elucidate how and to what extent such policies have impacted on it. Finally, based on its previous considerations, it succinctly analyses the references to higher education contained in the 2010 CONAE's Final Resolution. It concludes on the hope that the concretization of the National Education System will help redeeming the State's social debt as for the guarantee to provide quality education at all levels to the Brazilian people.

Key words: Higher education. National Education System. National Plan for Education. 2010 CONAE. Neoliberalism.

\section{Introdução}

$\mathcal{N}$

os anos mais recentes, surgiu um conjunto de termos novos para descrever as mudanças que vêm ocorrendo no campo da educação superior. Os autores falam de internacionalização, de mercado e bem público, de cooperação e comercialização, de privatização e ação governamental (Aupetit, 2009; Torres, 2009; Segrera, 2009; Rama, 2009). Estes termos designam aspectos de uma mudança em curso que vem transformando as relações estruturantes da educação superior. Segundo Aupetit (2009, p. 9), "são parte de uma doxa em vias de constituição, que pretende renovar (ou destruir) o contrato social no qual se fundamentou o pacto educativo na modernidade”. São, em parte, conceitos dicotômicos, pelos quais se manifestam ambivalências, resultantes de jogos de interesse relativos ao futuro da educação superior.

Internacionalização, empreendedorismo, diversificação, financiamento, empréstimos e bolsa de valores representam os novos rumos da educação superior que encontram abrigo em documentos de organizações internacionais, como a OCDE e a UNESCO, e se materializam na forma de acordos de livre comércio e convênios entre instituiçôes de ensino superior, colocando-as diante de novos objetivos e exigências, em termos de organização e estratégias. Muitas delas fazem da internacionalização uma de suas prioridades, por meio da colaboração interinstitucional, do intercâmbio de estudantes e pesquisadores, do reconhecimento mútuo de diplomas, da participação em pesquisas interinstitucionais e internacionais e da formação de profissionais com perfil internacional. $\mathrm{Na}$ 
avaliação de Aupetit (op. cit., p. 15-16), essa tendência de internacionalização “(...) contribui para a segmentação interna dos sistemas educativos nacionais", exigindo a "redefinição das atribuições dos governos nacionais para supervisionar sistemas educativos divididos em suas duas vertentes, nacional e transnacional" e tornando necessária uma "revisão das articulações desejáveis entre a ação pública e os provedores transnacionais mediante a regulação, a supervisão da qualidade e o financiamento".

Tais perspectivas suscitam o debate entre a educação entendida como bem público e a educação referida ao mercado, gerando tensões relativas às formas de financiamento, de prestação de contas e da privatização, instaladas desde a década de 1990 pelos governos nacionais. Desse embate resultou um novo e polêmico conceito de "bem público global", frequentemente usado pelos organismos internacionais como estratagema para desviar a atenção da contradição entre educação entendida como bem público e direito de todos e a educação vista como serviço com fins lucrativos, fornecido nos termos do Acordo Geral sobre Comércio de Serviços da Organização Mundial do Comércio (AGCS/OMC). Trata-se, neste caso, da constituição de um mercado educativo que não só reestrutura o campo da educação superior, mas chama à cena novos atores educativos, incidindo diretamente sobre a organização e atuação das instituições públicas da área. Encontramo-nos, portanto, diante de uma transformação de grandes proporções que nos obriga a repensar a noção de bem público e, por conseguinte, o papel e as obrigações do Estado quanto ao financiamento e a definição das políticas públicas em educação superior.

Todo este cenário internacional, que tenta se impor em nome de explícitos ou velados interesses econômicos, conflita com os interesses de projetos nacionais que, sem negar a necessidade da integração internacional, estejam comprometidos com o conceito de educação como um bem público e dever do Estado e, nessa perspectiva, com a autonomia dos sistemas nacionais de educação, pertinentes às necessidades econômicas, políticas e culturais de cada país.

Conscientes dessa realidade internacional e nacional, setores organizados da sociedade civil brasileira acompanham, com atenção crítica, o debate parlamentar em torno do Projeto de Reforma do Ensino Superior, atualmente em tramitação no Congresso e, em ativa colaboração com 
o Ministério da Educação, se engajam, mediante memorável processo democrático, na construção de um documento-base para um futuro Plano Nacional de Educação (PNE). Nas considerações reunidas no presente texto, pretende-se destacar, reconhecendo desde já as lacunas que a brevidade impõe, elementos do cenário internacional e nacional que representam, de certo modo, as condições e a moldura de um PNE. De outra parte, objetiva-se, ainda, pontuar aspectos relevantes, incorporados ao Documento Final da Conferência Nacional de Educação (CONAE, 2010), no que diz respeito à área de educação superior. A exposição segue um roteiro nucleado em torno de três tópicos, a saber: A educação superior no cenário internacional; breve olhar sobre a educação superior no Brasil; e, finalmente, a educação superior na perspectiva de um Sistema e de um Plano Nacional de Educação.

\section{A educação superior no cenário internacional}

A globalização que resulta do desenvolvimento científico-tecnológico nos campos dos meios de informação, das telecomunicações e dos meios de transporte transformou-se em globalismo econômico, levado a efeito com o objetivo de gerar maior acumulação de capital nos moldes da ideologia neoliberal, fomentada pelo capitalismo transnacional. $\mathrm{Na}$ formulação de Tünnermann Bernheim (2010 p. 27), esta vertente da globalização significa "livre mercado, desregulação, competitividade, individualismo, comunicações abertas, privatização do setor público", ou seja, "a globalização neoliberal, na qual claramente predominam os interesses do capitalismo transnacional”. Impõe-se uma visão economicista que passa a ditar os rumos da sociedade global contemporânea em todas as suas dimensões.

Particularmente a educação superior se ressente e, portanto, deve levar em consideração esta realidade planetária, com todas as implicações dela decorrentes, para o avanço da ciência e tecnologia, da cultura e do conhecimento. A globalização e a própria natureza do conhecimento geram um novo ethos instrumental, utilitário e comercial do conhecimento, afetando as atividades acadêmicas, cada vez mais condicionadas pelas exigências de aplicabilidade, utilidade e valor mercadológico. Esta tendência contrapõe-se à frustração da ideia-eixo da modernidade, segundo a qual a quantidade e aprofundamento do conhecimento garantiriam vida melhor para todos. Já é consensual que, em muitas dimensões, o 
conhecimento instrumental, indiscriminadamente aplicado, gera novos e complexos problemas, como confirma, por exemplo, a deterioração do meio ambiente. A busca de certezas científicas que norteou a sociedade nos séculos XIX e XX nos conduziu a um mundo de possibilidades e probabilidades, de in-certezas conflitivas, compreensíveis somente à luz de uma hermenêutica complexa e interdisciplinar. Referência central desse movimento é a ciência/tecnologia, instrumental e economicamente útil.

Trazendo este aporte para o campo da educação superior, Didriksson (1993, p. 23-24) lembra que "durante as últimas décadas ocorreu um reconhecimento explícito do caráter econômico que tem a educação superior, por sua particular relação com a produção de certo tipo de conhecimentos vinculados com a indústria e o desenvolvimento". Este contingente de conhecimentos, referenciados, por sua utilidade, à produção econômica, "tem importantes implicações na orientação e na estrutura atuais dos sistemas de educação superior". A estreita relação entre os conhecimentos desenvolvidos na academia e o sistema de produção ocorre em função da base científica das tecnologias modernas de produção. A inovação e criação tecnológica dependem, cada vez mais, de fatores exógenos, oriundos, por exemplo, de instituiçôes de pesquisa, acadêmicas ou não, externas ao próprio sistema de produção.

Em sentido inverso, as novas necessidades, geradas no setor produtivo, interferem nos rumos da pesquisa e, importante lembrar, da formação de recursos humanos na academia. O conhecimento científico, praticamente aplicável nos processos de produção, torna-se o novo valor de troca em substituição ao trabalho manual. Ainda segundo Didriksson (op. cit., p. 38), "a relação direta entre ciência, produção e tecnologia gerou um conjunto de novas categorias explicativas que indicam mudanças fundamentais na valoração do trabalho intelectual complexo e dos conhecimentos como valor econômico".

Por ser uma instituição diretamente voltada à produção do saber, desde o início dos debates sobre o valor econômico dos conhecimentos, considerou-se a instituição acadêmica e a universidade o lugar apropriado para a elaboração de conhecimentos e tecnologias estratégicas para o sistema de produção. No entanto, esta nova incumbência exigiria uma profunda transformação da universidade moderna, tradicionalmente focada na busca da verdade pura e neutra. O sentido prático, os enormes recursos técnicos, o trabalho em equipes institucionais, interinstitucionais, nacionais e internacionais, a comunicação virtual e 
a necessidade de resultados "úteis" são alguns dos elementos inovadores dos novos procedimentos epistêmicos que influenciam estruturalmente a universidade, exigindo dela acomodação às expectativas da globalização econômica. Como produtora de conhecimento, hoje matéria-prima dos processos produtivos, a universidade, envolvida pelos tentáculos da economia, tende, no limite, a transformar-se em prestadora de serviços, sujeita às regras do mercado, comandado pelas corporações transnacionais.

Em estreita relação com esta tendência, registra-se outra evolução no campo econômico, cujas diretrizes se encontram resumidas no famoso Consenso de Washington (1989). A tese central das políticas preconizadas pelo Consenso é a necessidade da redução do papel do Estado e a entrega de muitas de suas funções à iniciativa privada. Argumenta-se que, dessa forma, se alcançaria maior agilidade, eficiência e economia de recursos públicos. Ao Estado caberia investir na educação básica, entregando a educação superior ao mercado. $\mathrm{O}$ resultado foi o ingresso de algumas universidades na bolsa de valores, a criação de corporações acadêmicas supranacionais gestadas a partir de suas cedes nos países desenvolvidos, a organização de grandes redes internacionais de educação a distância e, sobretudo, a crescente transformação da educação em mercadoria ao encargo de empresas privadas interessadas no lucro. Fica evidente que esta nova orientação econômico/empresarial impacta não só sobre a autonomia, mas também sobre a identidade e a liberdade das instituiçôes de ensino superior.

Não mais a verdade e a formação são os eixos centrais, mas a produção de conhecimentos e a formação de profissionais adaptados e úteis ao mercado. As ações das universidades/empresas passam a ser negociadas no mercado internacional, segundo o potencial de lucros aferidos com os serviços que prestam. Tais serviços são analisados e avalizados não do ponto de vista de seu valor acadêmico/investigativo/formativo, mas de seu potencial de retorno financeiro. Estas duas tendências, ou seja, de um lado, a transformação do conhecimento/tecnologia em fator de produção e, de outro, a transformação da educação em empresa provedora deste tipo de conhecimento, ocorrem no contexto da globalização neoliberal e suas receitas para promover o ajuste macroeconômico.

Hoje, as instituições internacionais como o Fundo Monetário Internacional (FMI), o Banco Mundial (BM) e o Banco Interamericano de Desenvolvimento (BID) estão revendo sua posição desfavorável à educação 
superior, o que, no entanto, não significa o abandono de sua postura ideológica neoliberal. O que está por detrás do documento de autocrítica The World Bank's Economic Growth in the 1990's: Learning from a Decade of Reform é, do ponto de vista geral, o reconhecimento de que não há receitas únicas e, do ponto de vista específico da educação superior, que as universidades privadas comerciais não conseguem trazer o aporte científico e formativo que o mercado e as empresas necessitam. Esta constatação leva a chamar de volta a presença e o investimento estatal, não sem cobrar da universidade pública uma profunda reforma que lhe assegure, de um lado, pertinência em relação às reais necessidades do contexto em que está inserida e, de outro, garantia de qualidade compatível com a realidade internacional.

Nasce assim a tensão entre a pertinência global e a pertinência local, que pode ser melhor entendida lembrando a distinção que Tünnermann Bernheim (2010, p. 36) faz entre os conceitos de internacionalização e transnacionalização. Segundo este autor,

(...) enquanto na internacionalização se luta, seguindo as diretivas da Declaração mundial sobre a educação superior de 1998, por uma cooperação internacional solidária com ênfase na cooperação horizontal, baseada no diálogo intercultural e respeitosa da idiossincrasia e identidade dos países participantes, assim como o desenho de redes interuniversitárias e de espaços acadêmicos ampliados, na transnacionalização se trata de facilitar o estabelecimento em nossos países de filiais de universidades estrangeiras, de uma cooperação dominação, além disso, por critérios assistencialistas, assim como a venda de franquias acadêmicas, a criação de universidades corporativas auspiciadas pelas grandes empresas transnacionais, pelos programas multimeios e universidades virtuais, controladas por universidades e empresas dos países mais desenvolvidos.

Há, portanto, que separar os sentidos da globalização. Na medida em que internacionalização, no sentido usado por Tünnermann, parece um movimento necessário e irreversível no contexto do mundo contemporâneo, a transnacionalização, ao contrário, representa um risco que assola e ameaça o futuro da educação superior, porquanto coloca em risco o seu sentido de autonomia e pertinência social, o único a lhe conferir legitimidade e aceitação social. Nestes termos, poderíamos, então, dizer que o grande desafio que a internacionalização e a sociedade do conhecimento colocam é forjar um modelo de educação superior 
capaz de inovar, de transformar-se e participar tanto da transformação da realidade local e nacional, quanto de conectar-se às tendências internacionais de mundialização nos campos da pesquisa, tecnologia e formação profissional.

Os rumos do desenvolvimento da sociedade internacional globalizada, em particular no que diz respeito às formas de evolução, produção e divulgação do conhecimento, impõem à educação superior um leque de novas preocupaçôes relacionadas à qualidade, avaliação e acreditação; à pertinência econômica e social; aos processos de gestão e administração; ao aproveitamento das tecnologias de informação e comunicação; ao fortalecimento da cooperação internacional; ao exercício da autonomia universitária com responsabilidade social. Trata-se, na verdade, de uma nova cultura universitária: a cultura da gestão estratégica e eficaz, da pertinência social e democrática, da informática e comunicação, da pesquisa, ensino e extensão, da qualidade e avaliação, da transdisciplinaridade e abertura internacional, enfim, da formação cidadã crítica e cultural.

Todos estes elementos, aqui apenas sumariamente elencados, indicam que a educação superior se encontra num momento crucial de sua história, talvez só comparável àquele do nascimento da universidade moderna: o desafio de decidir sobre os rumos a seguir. Hoje se confrontam os caminhos do "capitalismo acadêmico" (Torres, 2009, p. 27), que atrela a educação superior ao mundo econômico e empresarial, e os da educação superior, entendida como bem público e direito de todos. Do nosso ponto de vista, as instituições de educação superior devem aliar-se ao projeto do Estado democrático, presente na sociedade de forma transparente, com estratégias claras e debatidas a favor do bem-estar de todos. A educação superior faz parte da esfera pública, na qual, além de promover o desenvolvimento da ciência/tecnologia e de formar profissionais cidadãos conscientes, deve constituir-se na ágora onde se gestam utopias que garantem a vida do povo e da nação. Para isso, se requer consciência política e determinação dos gestores, dos docentes, alunos e responsáveis pelas políticas públicas do setor, para, de um lado, resistir às exigências do neoliberalismo economicista e, de outro, promover a integração internacional.

\section{A educação superior no Brasil}

$\mathrm{Na}$ segunda metade do século passado, a educação superior brasileira passou por importantes mudanças que, iniciadas com expansão e a 
virada tecnológica durante o período militar, avançaram com a criação dos programas de pós-graduação durante os anos 1970 e foram retomadas após a década perdida de 1980, com a Lei de Diretrizes e Bases (LDB) de 1996 e suas leis complementares posteriores. $\mathrm{Na}$ fase mais recente dessas transformações, destacam-se os aspectos do aumento das matrículas, a retração do Estado e a privatização, a maior internacionalização e transnacionalização, o aumento das matrículas femininas e, finalmente, a introdução de um sistema de avaliação da educação superior.

Contudo, foi a partir dos anos de 1990, no contexto das mudanças globais e latino-americanas, que a universidade brasileira vem passando pelas mais importantes inovações, principalmente no nível da graduação. Analisando tais transformações, Dias Sobrinho e Brito (2008, p. 488) lembram os

(...) dois principais desafios [que] oferecem os motivos para estas mudanças: aumentar a competitividade da economia no mundo globalizado através incremento na formação de profissionais e, por outro lado, o fortalecimento de valores democráticos, em especial da equidade, através da ampliação das oportunidades de acesso e permanência e o fortalecimento dos valores adequados à formação cidadã.

Os autores apontam, ainda, como a mais importante característica dessas mudanças a expansão do setor privado com fins lucrativos e de duvidosa qualidade, com a consequente intensificação da funcionalidade econômica e utilitarista da educação superior.

A primeira medida tomada para incrementar o aporte da educação superior ao desenvolvimento da economia foi a ampliação de sua abrangência quantitativa. Efetivamente, a expansão que aconteceu principalmente nas décadas de 1960 e 1970 tornara-se muito mais lenta nas duas décadas posteriores. $\mathrm{O}$ número de instituições públicas ficou, neste período, praticamente inalterado, com exceção das instituiçóes públicas estaduais que cresceram na década de 1980 . Tal fato explica-se, primeiro, pela falta recursos públicos para investimento na área e, segundo, pelas pressóes externas advindas das receitas do BM, do FMI e do BID, os três principais braços do neoliberalismo internacional. Com relação à escassez de recursos, pode-se dizer que ela foi real, sobretudo, no contexto da estagnação econômica registrada na chamada década perdida dos anos de 1980. Quanto à política neoliberal, agenciada pelas suas instituições internacionais, resta reconhecer que teve reflexos diretos e nefastos sobre os 
serviços sociais públicos assegurados pelo Estado, entre eles a educação, a saúde e a seguridade.

Já desde o final da Segunda Guerra, o BM, em consistente parceria com o FMI, vinha defendendo estratégias político-econômicas que visavam fortalecer e universalizar o ideário neoliberal, cujos princípios foram propostos pelo economista inglês John Willianson e fixados no Consenso de Washington. O eixo principal das teses reunidas nesse documento é o da supremacia do econômico sobre as outras dimensões da vida social, cultural e política, a redução da presença do Estado e o fortalecimento da iniciativa privada. A partir da década de 1980, estas estratégias políticas tornaram-se determinantes para a educação superior no Brasil. Operacionalmente, critica-se a suposta ineficiência do Estado na gestão de recursos públicos, exigindo-se, na sequência, a redução do Estado e a transferência de boa parte de seus encargos para a iniciativa privada.

São especialmente dois documentos - a saber, La enseñanza superior: las lecciones derivadas de la experiencia (Banco mundial, 1994) e The financing and management of higher education: a status report on worldwide reforms (Banco Mundial, 1998) - que desenham as orientações do Banco para desenvolvimento futuro da área de educação superior. Partindo da constatação da importância da área para o desenvolvimento socioeconômico, o Banco destaca quatro pontos-chave que deveriam nortear as políticas para o setor: complementar os recursos do Estado, sobretudo com o fim da gratuidade da educação superior pública; promover a diferenciação institucional; encorajar as iniciativas do setor privado com concessão de maior autonomia; e abrandar regulamentos e normas oficiais (cf. Sguissardi, 2009).

Estas orientações foram apresentadas, de certo modo, como conditio sine qua non, uma vez que, segundo o Banco, de sua implementação dependeriam as chances dos países periféricos de se integrarem ao desenvolvimento da economia mundial globalizada, para a qual não haveria alternativas de desenvolvimento no futuro. Daí resultou

(...) a profunda influência de seus diagnósticos e orientações sobre a educação superior junto às políticas públicas da maioria dos países. E isto se dá em áreas como as da legislação, do processo de privatização e diferenciação institucional, do financiamento público e diversificação de fontes de recursos, e de natureza das instituições, entre outras. (Sguissardi op. cit., p. 65) 
O ponto fulcral e, hoje, certamente, também o mais polêmico é o entendimento do Banco e de seus técnicos de que a educação superior não pode ser vista como um bem estritamente público. A partir dessa premissa argumenta-se a favor da competitividade, do financiamento alternativo e da privatização.

Todas essas orientações tiveram forte impacto em função dos condicionantes macroeconômicos que mantinham os países em desenvolvimento sob pressão e quase incondicional aceitação. Deve-se, no entanto, reconhecer que boa parte da responsabilidade pela implantação das premissas neoliberais recai sobre os ombros não apenas dos órgãos internacionais, mas também dos governos e elites econômicas locais. De todos os modos, as políticas adotadas implicam uma reorientação de rumo da educação superior no sentido da retração do Estado, cuja função deveria, de ora em diante, centrar-se na tarefa de regular, avaliar e controlar a iniciativa privada, à luz do critério custo-benefício e do predomínio econômico/mercadológico. Disso tudo resulta o processo de privatização e mercadorização da educação superior, hoje tema central das preocupações e debates na área. O ajuste neoliberal gera um novo ethos acadêmico de redução do papel do Estado e ampliação do papel do mercado.

Os principais argumentos usados para justificar o incremento da educação privada são a ineficácia dos gastos públicos, a baixa oferta de vagas, a rigidez curricular, a escassa utilidade da educação superior pública para a economia, em especial, para a indústria. Na tentativa de superar estes gargalos e atendendo às prerrogativas da ideologia neoliberal, iniciou-se um processo de privatização de amplas consequências. Os resultados dessa política são assim resumidos por Dias Sobrinho (2010, p. 287):

(...) grande expansão quantitativa de instituições e de matrículas estudantis, forte movimento de privatização e de incorporação de lógicas mercantis, internacionalização e transnacionalização, aumento de oferta de serviços virtuais e de educação a distância, aparecimento de novos tipos de provedores. Diversificação, segmentação e diferenciação de instituiçôes, novas modalidades de financiamento, mudanças nos perfis dos estudantes, demandas de mais estreita vinculação entre as instituições educativas e as empresas e empregos. Esse quadro trouxe à tona a questão da qualidade, ressignificada para melhor se ajustar às novas realidades econômicas, e da garantia da qualidade, mediante a acreditação. 
Educação superior na perspectiva do Sistema e do Plano Nacional de Educação

A partir de 1996, registrou-se, efetivamente, uma grande expansão de vagas no setor privado mercantil, em contraposição à quase-estagnação do setor público. Segundo Sguissardi (2010, p. 307),

(...) cabe observar que, após o ajuste neoliberal na economia e a reforma do Estado, de 1994 a 2008, para um crescimento global do número de IES de $164,6 \%$, as públicas cresceram apenas $8,3 \%$ contra $218,5 \%$ das privadas. Quanto às matrículas, para um crescimento global de 205,8\%, as públicas cresceram $84,6 \%$ contra $292,4 \%$ das privadas.

Hoje, cerca de $80 \%$ das matrículas concentram-se no setor privado e $20 \%$ no setor público. Dos alunos concluintes, em torno de $70 \%$ se formam em instituiçôes privadas e os restantes 30\% em instituições públicas federais, estaduais ou municipais. Constata-se também que o número de vagas oferecidas ainda não corresponde à procura, fazendo com que a educação superior, além de privatizada, siga sendo muito elitista. Acrescente-se que, além da privatização propriamente dita, encontra-se há tempos em discussão a necessidade de as universidades públicas buscarem, por conta própria, fontes alternativas de financiamento. Isto tem induzido as universidades públicas a estreitarem suas relações com empresas, ocupando, assim, um espaço obscuro que se costuma designar de quase-mercado. Com isso, também a educação superior pública se torna, em preocupante medida, uma instituição de prestação de serviços, regida pelas leis do mercado. A desestatização da educação superior publica segue, veladamente, o rastro traçado pela ideologia neoliberal da privatização do público.

Estas políticas que foram sendo implantadas ao longo da década de 1990 não sofreram grande mudança de rumo nos anos mais recentes, embora tenham sido feitos investimentos na criação de novas universidades federais e na geração de programas democratizantes de acesso e permanência na educação superior. Com o objetivo de superar as dificuldades que vêm sendo apontadas e criticadas pelos especialistas da área, foi dado início, ao longo dos últimos anos, a um processo de reformas da educação superior que, parcialmente, foi sendo incrementado através de medidas pontuais, mas que também se materializou num projeto de reforma que atualmente tramita no Congresso Nacional.

Seria, portanto, leviano afirmar que a educação, e a educação superior em particular, não são prioridade do atual governo. A criação de novas universidades públicas, a concessão de mais recursos, a política 
salarial mais adequada, bem como o fomento de políticas afirmativas demonstram o contrário. Não se pode esquecer, no entanto, que o Brasil apresenta um dos sistemas de educação superior mais mercantilizados do mundo: $73 \%$ das matrículas e $90 \%$ das instituições são do setor privado. O que está em jogo são o papel e o dever do Estado como responsável pela educação pública, básica e superior, de qualidade para todos. Como esta não é a tese defendida por boa parte dos parlamentares que deverão decidir sobre o mencionado projeto de lei, pode-se prever grande dificuldade na aprovação, pelo menos não sem cortes, emendas e vetos que podem ameaçar o seu sentido principal. Esta conclusão parece condizente com a continuidade da política neoliberal no atual e, muito provavelmente, nos próximos governos.

\section{A educação superior na perspectiva do Sistema e do Plano Nacio- nal de Educação: impasses e perspectivas}

A exitosa iniciativa da CONAE (2010), a par de ter-se constituído num marco histórico para a educação brasileira na contemporaneidade, representa, ela mesma, o reconhecimento das enormes dívidas sociais do Estado com relação à educação da população brasileira. As lutas antigas, iniciadas ainda na primeira metade do século passado com o Movimento dos Pioneiros da Educação, fortemente retomadas depois do período militar através da realização das conferências e congressos nacionais de educação, conseguiram assegurar, tanto na Constituição quanto na Lei de Diretrizes e Bases da Educação Nacional, a educação como direito social garantido pelo Estado. Este respaldo jurídico, no entanto, não garantiu a efetiva implementação da educação de qualidade como direito social e política de Estado.

De fato, no cenário internacional, o Brasil apresenta uma das mais altas concentraçōes de renda do mundo, com $50 \%$ da população de pessoas em situação de pobreza, denotando uma crônica ausência de políticas sociais efetivas. Este panorama de exclusão reflete-se, também, no campo da educação, onde cerca de $11 \%$ continuam analfabetos, $27 \%$ têm até três anos de escolaridade e $60 \%$ da população não possui o ensino fundamental completo. Esta realidade permite concluir que o termo Sistema Nacional de Educação vem sendo usado, até o momento, de forma equivocada, uma vez que, na verdade, tal sistema nunca foi efetivado. 
Daí a importância do engajamento de setores importantes da sociedade civil e política em prol da construção de um Sistema Nacional de Educação e de um Plano Nacional de Educação, como política de Estado. Não se trata de outra coisa, senão do projeto de elaboração de políticas de Estado para a educação nacional, visando à efetivação do direito social à educação. Segundo o Documento Final da CONAE (2010), os pontos imprescindíveis para "assegurar, com qualidade, a função social da educação e das instituições educativas" são

(...) a educação inclusiva; a diversidade cultural; a gestão democrática e o desenvolvimento social; a organização e institucionalização de um Sistema Nacional de Educação, que promova de forma articulada, em todo o país, o regime de colaboração; o financiamento e acompanhamento e o controle social da educação; a formação e valorização dos/das trabalhadores/as da educação. (CONAE, 2010, p. 13)

A indicação dessas concepções, proposições e potencialidades para as políticas nacionais de educação sinaliza a efetivação da garantia de educação de qualidade para todos/as, constituindo-se em marco para a construção do novo PNE

(...) que estabeleça mecanismos para: erradicar o analfabetismo; universalizar o atendimento escolar; melhorar a qualidade do ensino; formar para o pleno exercício da cidadania e para o trabalho; e promover humanística, científica e tecnologicamente o País, preservando a diversidade regional e cultural. (Idem, ibid., p. 22)

Todos esses pontos referem-se à educação nacional em seu conjunto, ou seja, tanto à educação básica quanto à superior, visando o acesso e permanência com qualidade para todos como dever do Estado. Assim, embora o país já disponha de respaldo jurídico e estrutura administrativa, ainda não se conseguiu encontrar uma forma de organização capaz de viabilizar os objetivos de uma educação como direito de todos, garantido pelo Estado. Um dos pontos de impasse dessa alarmante situação da educação nacional é a falta de um regime que assegure a colaboração entre a Federação, os estados e os municípios. Superar este gargalo é, portanto, uma das tarefas mais urgentes e, certamente, também, mais ingentes para alcançar os princípios explicitados no artigo 206 da Constituiçãoo Federal. 
Embora o regime de colaboração entre os entes federados (Federação, estados/Distrito Federal e municípios) esteja previsto na Constituição, este dispositivo ainda não foi regulamentado para a educação como um todo. As universidades são um caso especial, porque a Constituição Federal reserva para elas autonomia didático-científica, administrativa e de gestão financeira e patrimonial (CF, 1988, art. 207). Cabe ao Estado garantir, efetivamente, o cumprimento desse dispositivo constitucional, tanto nas instituiçôes por ele mantidas quanto, também, nas instituições de ensino superior privadas, nas quais a autonomia é, muitas vezes, usufruída apenas pelas mantenedoras e não pelas instituições universitárias como deveria ser (CONAE, 2010, p. 23).

Um Sistema Nacional de Educação assumido pelos entes federados deve oferecer a moldura sistêmica e jurídica para definir, no corpo do PNE, as diretrizes, objetivos, metas e estratégias de implementação, manutenção e desenvolvimento da educação em todos os níveis e modalidades, desde a creche até a pós-graduação. Para a realização do regime de colaboração mútua, previsto na Constituição, os encaminhamentos da CONAE (2010) sugerem a elaboração/efetivação de um Projeto político-pedagógico para a educação básica e um Plano de desenvolvimento institucional para a educação superior, no âmbito das instituições educativas públicas e privadas (idem, ibid., p. 28). Para o acompanhamento, avaliação e controle de todo este processo sugere-se a criação de uma lei de responsabilidade educacional, que defina a forma e os meios de penalizar, em caso de descumprimento dos dispositivos legais determinados, os responsáveis pela gestão e pelo financiamento da educação nos âmbitos federal, distrital, estadual e municipal.

Todas estas medidas devem abranger tanto as instituiçôes públicas quanto as privadas, previstas na Constituição e na LBD. Portanto, também

(...) as instituições do setor privado, por fazerem parte do Sistema Nacional de Educação, subordinam-se ao conjunto de normas gerais de educação e devem se harmonizar com as políticas públicas, que têm como eixo o direito à educação, e acatar a autorização e avaliação desenvolvidas pelo poder público. Dessa forma, no que diz respeito ao setor privado, o Estado deve normatizar, controlar e fiscalizar todas as instituições, sob os parâmetros e exigências aplicadas ao do setor público. (CONAE, 2010, p. 31) 
Um dos princípios constitucionais que regem o ensino público é o da gestão democrática das instituiçôes. Na educação superior, tal princípio se articula com o da autonomia universitária, condição precípua da vida acadêmica. O tema da autonomia é hoje bastante controverso, em função de certa discrepância existente entre o texto da Constituição Federal, o qual determina que as universidades devem ter autonomia didático-científica, administrativa, gestão financeira e patrimonial, e o texto da LDB que, em seu artigo 54, diz: "as universidades mantidas pelo poder público gozam de estatuto jurídico especial para atender as peculiaridades de sua estrutura, organização e financiamento pelo poder público, bem como para estabelecer os planos de carreira e o regime jurídico do seu pessoal".

Esta questão adquire particular complexidade no contexto da diferenciação e diversificação da educação superior no Brasil, de natureza pública, comunitária ou privada, prevista na Constituição Federal. No caso das comunitárias, há a importante interveniente das fundações, que chamam a si o direito à autonomia e o restringem à instituição acadêmica. Nas instituições privadas, por sua vez, coloca-se a questão da gestão democrática que, muitas vezes, encontra restrições no tocante à liberdade de expressão de ideias e à gestão democrática. A gestão democrática é um princípio constitucional que garante condições de igualdade, liberdade, justiça e diálogo entre todas as esferas, como espaço de deliberação coletiva e que, portanto, precisa ser respeitada e praticada por todas as instituições educacionais. Tanto instituições públicas quanto privadas devem, pois, garantir a participação de todos os envolvidos no processo acadêmico, na definição de suas políticas educacionais, mediante o pleno funcionamento de seus conselhos e órgãos colegiados, visando garantir espaços articulados de decisão e deliberação.

A CONAE defende a gestão democrática da educação, tanto pública quanto privada, como um pressuposto fundamental da educação de qualidade. A qualidade é, evidentemente, complexa e abrangente conforme as circunstâncias, os fatores intra e extra-institucionais, as dimensões socioeconômicas, a disponibilidade de recursos etc. Por isso, é necessário estabelecer um padrão de qualidade, mas este não pode ser único em função das dimensôes, fatores e condições circunstanciais. $\mathrm{O}$ entendimento deve ser resultado de um amplo debate que leve em consideração o contexto, o momento histórico, as condições sociais e culturais que envolvem cada instituição. Por isso, a CONAE destaca a "qualidade social" 
que, além dos aspectos da aquisição de conhecimentos e habilidades, implica, também, uma "formação sólida, crítica, criativa, ética e solidária" (CONAE, 2010, p. 48).

Além da clara compreensão do que significa qualidade, é necessário estabelecer mecanismos de avaliação dessa qualidade. Após bastante resistência, nos anos mais recentes, acompanhando as tendências internacionais, a avaliação tornou-se, também no Brasil, um dos eixos centrais da política educacional. Para a educação superior foram desenvolvidos o Sistema Nacional de Avaliação da Educação Superior (SINAES) e o Sistema de Avaliação da Pós-Graduação e Pesquisa. Supõe-se que a avaliação ajude a alterar objetivos, valores e processos; que amplie o poder de regulação e controle por parte do Estado; que reconstitua o sistema de relacionamento entre as instituições e que promova mudanças na gestão, pesquisa, extensão e na formação profissional.

As grandes dúvidas e suspeitas que pairam sobre os processos avaliativos dizem respeito ao seu modus operandi. São recorrentes e disseminadas as críticas aos critérios supostamente muito quantitativistas e produtivistas, vindas especialmente do campo das ciências humanas e sociais que se sentem expostas a critérios avaliativos não condizentes com sua natureza epistêmica. Para evitar uma exagerada centralidade conferida à avaliação, o controle nocivo e a competição institucional,

(...) sinaliza-se a necessidade de novos marcos para os processos avaliativos, incluindo sua conexão à educação básica e superior, aos sistemas de ensino e, sobretudo, assentando-os em uma visão formativa, que considere os diferentes espaços e atores, envolvendo o desenvolvimento institucional e profissional. (Idem, ibid., p. 53)

O novo enfoque recai sobre a melhoria da educação como eixo orientador de todo o processo avaliativo no campo da educação. Para atingir este objetivo, a avaliação central precisa tornar-se flexível, compreendendo que o sucesso ou o fracasso escolar resultam de uma série de fatores extra e intraescolares (condição social, regional, cultural, salários, infraestrutura, gestão etc.) que devem ser levados em consideração. Defende-se, portanto, uma concepção ampla de avaliação apta a, antes de tudo, "incorporar o atributo da qualidade como função social da instituição educativa e a articulação entre os sistemas de ensino, em todos os níveis, etapas e modalidades (...)" (idem, ibid., p. 55). No caso da educação superior, 
(...) é preciso aprimorar o processo avaliativo, tornando-o mais abrangente, de modo a promover o desenvolvimento institucional e a melhoria da qualidade da educação como lógica constitutiva do processo avaliativo emancipatório, considerando, efetivamente, a autonomia da IES, a indissociabilidade entre ensino, pesquisa e extensão. Além disso, faz-se necessária maior interrelação das sistemáticas de avaliação da graduação e da pós-graduação, na constituição de um sistema de avaliação para a educação superior. (p. 56)

A demanda social por educação pública implica produzir instituições democráticas e de qualidade social que garantam o acesso ao conhecimento, à formação profissional e aos bens culturais produzidos e acumulados pela sociedade, na perspectiva de uma formação crítica e emancipadora, a partir dos contextos concretos. No que se refere à educação superior, constata-se que esse nível de ensino continua elitista e excludente. A expansão ocorrida ao longo das duas últimas décadas, embora alentadora, ainda está longe de atingir os parâmetros de uma real democratização, sobretudo, porque tal expansão se deu, como vimos antes, pela via da privatização, ou seja, do ensino pago e da oferta sem qualidade. Nem mesmo os planos de inegável mérito e com importantes reflexos sobre a questão central do financiamento, tais como o Programa de Apoio a Planos de Reestruturação e Expansão das Universidades Federais (REUNI) e o Programa Universidade para Todos (PROUNI), não conseguiram atender às expectativas da população. Até hoje, no Brasil, apenas cerca de 13\% dos jovens entre 18 e 24 anos estão cursando o ensino superior e, destes 13\%, 75\% estão matriculados no setor privado. De outra parte, as estatísticas mostram que os brancos representam $52 \%$ da população e $73 \%$ na educação superior.

Diante dessas injustiças e dívidas históricas do Estado brasileiro com relação a certos setores da população, a CONAE expressa a ambiciosa meta de "reserva de vagas nas IES para um número mínimo de $50 \%$ de estudantes egressos/as das escolas públicas, respeitandose a proporção de negros/as e indígenas em cada ente federado" (CONAE, 2010, p. 66). E preciso ampliar, ainda mais, a criação de instituições e a oferta de vagas na educação superior, priorizando setores carentes da população, historicamente excluídos, e as regiōes distantes dos grandes centros urbanos. Para garantir, efetivamente, o direito à educação superior obstaculizado pela falta de vagas e, em certos setores, pela enorme desigualdade social, exige-se a atenção e a ação 
permanentes do Estado, reconhecendo a educação superior de qualidade como um bem público, direito de todos e, portanto, dever do Estado.

Porém, todo esforço será inócuo, se não for acompanhado de ações sistemáticas e consistentes de melhoria na formação inicial e continuada de profissionais bem preparados em suas especialidades, com uma base interdisciplinar de cultura e eticidade. É preciso criar uma política nacional de formação de profissionais, tanto para a educação básica quanto para a superior, em consonância com as atuais demandas sociais, epistêmicas, tecnológicas e culturais da sociedade, capazes de aproveitar adequadamente as novas tecnologias de informação e comunicação, no contexto das diferentes linguagens midiáticas.

Daí a necessidade de um Sistema Nacional articulado de Educação e de um Plano Nacional de Educação, norteados pela "firme concepção da educação como direito humano fundamental, direito público e dever do Estado" (CONAE, 2010, p. 105-106). Para viabilizar este projeto, a CONAE entende como imprescindíveis os seguintes pontos: regulamentar o regime de colaboração entre os entes federados; construir um regime de colaboração entre os órgãos normativos dos sistemas de ensino nacionais, estaduais e distritais; ampliar o investimento em educação, em relação ao PIB; definir e aperfeiçoar os mecanismos de acompanhamento, fiscalização e avaliação; ampliar o atendimento dos programas de renda mínima; estabelecer uma política nacional de gestão educacional; garantir a autonomia pedagógica, administrativa e financeira das instituiçôes; criar instrumentos que garantam a transparência na utilização dos recursos públicos; estabelecer mecanismos democráticos de gestão; definir o financiamento, em regime de colaboração entre os entes federados.

Com relação às políticas de financiamento sugere: desvincular os recursos destinados à educação de qualquer nível de contingenciamento de recursos provenientes das receitas da União, dos estados e municípios; revogar de imediato a Desvinculação das Receitas da União (DRU) para todas as áreas sociais; garantir o aumento dos recursos da educação de $18 \%$ para $25 \%$, no caso da União, e de $25 \%$ para $30 \%$, no caso dos estados e municípios; efetivar a responsabilização administrativa e fiscal dos gestores que não executarem na integralidade os recursos destinados à educação; retirar as despesas com aposentados e pensionistas 
da conta dos recursos destinados à educação em nível federal, estadual e municipal.

Quanto ao financiamento, recomenda: realizar estudos para criar um Fundo de Manutenção e Desenvolvimento da Educação Superior Pública; estabelecer parâmetros para a distribuição de recursos; definir as condições a serem satisfeitas pela União, estados e municípios para terem acesso aos recursos deste Fundo de Manutenção e Desenvolvimento da Educação Superior Pública; garantir recursos orçamentários para que as universidades possam definir e executar suas atividades; alocar recursos financeiros específicos para a expansão da graduação no período noturno; definir parâmetros de qualidade para as instituições de educação superior e estabelecer o volume mínimo de recursos a serem destinados às atividades de ensino, pesquisa e extensão; estabelecer programas de apoio à permanência dos alunos na instituição; ampliar o debate sobre os programas PROUNI e REUNI, visando sua ampliação e fortalecimento; garantir recursos para as políticas de acesso e permanência na educação superior para grupos sociais tradicionalmente excluídos; garantir recursos do governo federal para a oferta de cursos superiores aos profissionais da educação.

Todas estas reivindicações, por mais utópicas que pareçam, são aspectos de uma enorme dívida social que o Estado tem com o povo brasileiro. Para que tal dívida possa ser sanada, exige-se uma clara decisão política em favor de uma educação concebida como processo democrático, com a harmônica e universal cooperação de todos os entes federados, que garanta a educação de qualidade como direito de todos independente de condição social, raça, gênero, religião etc. Os resultados da CONAE representam uma oportunidade única para que os gestores das políticas públicas da área e, posteriormente, os parlamentares da Câmera dos Deputados e do Senado Federal atendam aos históricos anseios da população brasileira. Esta responsabilidade política de Estado, livre de quaisquer interesses setoriais ou econômicos, deve refletir-se, primeiro, na construção de um Sistema Nacional de Educação integrado, democrático e inclusivo e, segundo, na elaboração de um Plano Nacional de Educação que defina estratégias de efetivação de uma educação democrática, inclusiva e de qualidade para todos/as, como forma de realização plena, profissional e ética, das pessoas e da coletividade. 


\section{Conclusão}

Inicialmente, foi desenvolvida uma argumentação que procurou mostrar alguns condicionamentos da educação no contexto do mundo globalizado contemporâneo. Nesse cenário, foi de grande relevância para a educação superior, ao longo das últimas décadas, o predomínio da ideologia neoliberal que apostou no economicismo e no privatismo. $\mathrm{O}$ receituário neoliberal que promove o ajuste macroeconômico reflete-se, direta e concretamente, sobre a educação superior. Um dos pontos desse ajuste, imposto aos países em desenvolvimento como forma de equilibrarem suas economias e acelerarem seu desenvolvimento, deveria ser a redução do Estado e a entrega de boa parte de suas funçôes à iniciativa privada. Foi esta receita que modificou o cenário da educação superior na América Latina, cujos governos nacionais, em sua maioria, aderiram a estas sinalizações, dando início à retração do Estado e, com isso, à privatização do ensino e à internacionalização da educação.

Exemplo paradigmático desse desenvolvimento é o sistema de educação superior brasileira que, ao longo das últimas décadas, proveu sua expansão pela privatização. Efetivamente, a partir dos anos de 1990, registra-se a retração do Estado e a transferência de boa parte de suas responsabilidades, no campo da educação, para o setor privado. Mesmo reconhecendo os avanços dos anos mais recentes, no tocante à expansão da educação superior e às políticas afirmativas das quotas, do REUNI e PROUNI, é preciso não esquecer que boa parte dessas medidas foi alcançada pela privatização e, em regra, sem garantias de qualidade. Embora não se possa esperar para um futuro próximo uma reversão radical da marcha neoliberal, há sinais de que a luta por uma educação pública de qualidade como um direito de todos e responsabilidade do Estado alcance, pela consciência e força popular, significativos avanços.

A realização da Conferência Nacional de Educação transformouse num marco auspicioso, animador e paradigmático dessa luta. É a primeira vez no Brasil e, salvo melhor juízo, também na América Latina que se prepara um Sistema Nacional de Educação e se oferece elementos para a construção de um Plano Nacional de Educação a partir das bases. Ou seja, com a participação de todos os/as cidadãos/ãs interessados/as, escolas, universidades, ONGs, secretarias municipais e estaduais de Educação, sociedades científicas, sindicatos, representações estudantis e, ao mesmo tempo, com o efetivo apoio do Ministério da Educação. 
Desse amplo e complexo movimento resultou um documento rico e democrático que restaura, de forma veemente, firme e inconfundível, a tese da educação pública de qualidade como direito de todos e dever do Estado. Agora depende do Ministério da Educação encaminhar ao Congresso Nacional um projeto de lei que respeite as metas estabelecidas pela Conferência, conforme se encontram registradas no seu Documento Final.

Um dos maiores desafios para uma efetiva articulação entre justiça social, educação e trabalho é a atuação afirmativa do Estado, como promotor da justiça e do bem-estar individual e coletivo. Somente através de políticas sociais afirmativas, promovidas pelo Estado, pode-se alimentar a esperança na superação das injustiças, desigualdades e enormes dívidas históricas com os grupos minoritários e desprivilegiados. O Estado deve garantir a todos, através de estratégias adequadas de implementação, o acesso e a permanência no sistema educacional básico e superior. A universidade deve agregar-se e participar proativamente do esforço geral da sociedade por uma vida e um mundo melhores, tanto através de suas atividades precípuas de ensino, pesquisa e extensão, quanto, também, de ações afirmativas que ultrapassem estes limites.

Recebido e aprovado em setembro de 2010.

\section{Referências}

AUPETIT, S.D. De la internacionalización acadêmica a la comercialización de los servicios educativos. Pensamiento Universitário, Buenos Aires, v. 12, n. 12, p. 9-29, oct. 2009.

CONFERÊNCIA NACIONAL DE EDUCAÇÃO (CONAE), 2010, Brasília, DF. Construindo o Sistema Nacional Articulado de Educação: o Plano Nacional de Educação, diretrizes e estratégias; Documento Final. Brasília, DF: MEC, 2010. Disponível em: <http://conae.mec.gov.br/ images/stories/pdf/pdf/documetos/documento_final.pdf>

DIAS SOBRINHO, J.; RISTOFF, D. (Org.). Avaliação e compromisso público. Florianópolis: Insular, 2003. p. 125-157.

DIAS SOBRINHO, J. Acreditação da educação superior. In: LoPEZ Segrera, F.; Rivarola, D.M. La universidad ante los desafios del siglo XXI. Asunción: Ediciones y Arte, 2010. p. 261-294. 
DIAS SOBRINHO, J.; BRITO, M.R.F. La educación superior en Brasil: principales tendencias y desafios. Avaliação, Sorocaba, v. 13, n. 2, p. 487-507, jul. 2008.

DIDRIKSSON, A. Universidad del futuro. Mexico, DF: Universidad Nacional Autónoma de México, 1993.

LOPEZ SEGRERA, F. Escenarios mundiales y regionales de la educación superior. In: LAMARRA, N.F. Universidad, sociedad y inovación. Caseros: EDUNTREF, 2009. p. 57-67.

LOPEZ SEGRERA, F.; RIVAROLA, D.M. (Comp.). La universidad ante los desafios del siglo XXI. Asunción: Ediciones y Arte, 2010.

RAMA, C. La tendência a la internacionalización de la educación superior. In: LAMARRA, N.F. Universidad, sociedad y inovación. Caseros: EDUNTREF, 2009. p. 43-56.

SGUISSARDI, V. Universidade brasileira no século XXI: desafios do presente. São Paulo: Cortez, 2009.

SGUISSARDI, V. Mercantilização e intensificação do trabalho docente: traços marcantes da expansão universitária brasileira hoje. In: LOPEZ SEGRERA, F.; RIVAROLA, D.M. La universidad ante los desafios del siglo XXI. Asunción: Ediciones y Arte, 2010. p. 295-315.

TORRES, C.A. La educación superior en tiempos de la globalización. In: LAMARRA, N.F. Universidad, sociedad y inovación. Caseros: EDUNTREF, 2009. p. 57-67.

TÜNNERMANN BERNHEIM, C. La educación superior necesária para el siglo xxi. In: Lopez Segrera, F.; RivarolA, D.M. (Comp.). La universidad ante los desafios del siglo XXI. Asunción: Ediciones y Arte, 2010. p. 25-69. 